\title{
The Effect of Floor Aerobics Exercise on Immunity Induction of People Living with HIVIAIDS: The Case of "Yetessfa Bisrat Miskir Association", Dire Dawa, Ethiopia
}

\author{
Yenehun Taye \\ Department of Sport Science, Dire Dawa University, Dire Dawa, Ethiopia \\ Email address: \\ yenehun2003@gmail.com
}

\section{To cite this article:}

Yenehun Taye. The Effect of Floor Aerobics Exercise on Immunity Induction of People Living with HIV/AIDS: The Case of "Yetessfa Bisrat Miskir Association”, Dire Dawa, Ethiopia. International Journal of Immunology. Vol. 4, No. 2, 2016, pp. 6-12. doi: $10.11648 /$ j.iji.20160402.11

Received: July 12, 2016; Accepted: July 21, 2016; Published: August 15, 2016

\begin{abstract}
There is much scientific evidence that indicates that physical exercise training is not only appropriate but also warranted for patients with HIV/AIDS. The study was carried out to identify the effects of floor aerobic exercise on immunity induction of people with HIV/AIDS Anti Retroviral Therapy (ART) users. A convenience sample of 26 subjects (26 male and 26 female participants) between the age of 30 and 50 years (mean 38.6) were participated with a minimum of 28 and maximum 36 sessions. The study aimed to compare of the results before and after exercise of the study subjects and also with respect to sex difference. A component of T-cells of PETR compared with POETR has shown that significantly difference at the probability level of 5\% except CD8 count. The mean comparison of Females and Males components of T-cells count PET compared with POET has shown that significantly difference at the probability level of $5 \%$ except the mean value of male CD8 result. In total sample mean difference of T-cells $\left(C D 4=279, \mathrm{CD} 8=104, \mathrm{CD} 3=426 \mathrm{cells} / \mathrm{mm}^{3}\right.$ and $\left.\mathrm{CD} 4 / \mathrm{CD} 8 \mathrm{ratio}=0.2\right)$; The same parameters for male subjects mean difference of T-cells $\left(C D 4=296.15, C D 8=38, C D 3=486.61 \mathrm{cell} / \mathrm{mm}^{3}\right.$, ratio of CD4 to $\mathrm{CD} 8=0.22$, These findings suggest that increasing duration, frequency, modality and intensity of floor aerobics exercise might have beneficial effects on immunity induction in people with HIV/AIDS.
\end{abstract}

Keywords: Floor Aerobic Exercise, Immunity, HIV/AIDS

\section{Introduction}

\subsection{Background of the Study}

Sedentary behavior, widely prevalent in developed countries is associated with a variety of diseases and with increased mortality [1]. However, physical activity clearly demonstrates beneficial effects on several health issues, including cardiovascular and all causes of mortality [2]. Among beneficial impacts of exercise we can identify a robust effect on cardiovascular outcomes inducing improvements in lipoproteins and body composition that are translated into reductions in risk of coronary disease, cardiac and probably stroke events [3], and cardiovascular deaths [4]. In this way, aerobic exercise improves insulin sensitivity, glycemic and blood pressure control, decreasing the risk of new onset diabetes, hypertension and obesity (with secondary beneficial effects). Besides this, a modest effect in prevention of breast, intestinal and pancreatic cancer $[5,6]$ and an increment in bone mineral density (indeed reductions in hip fracture risks in patients with osteoporosis) have been established. Neuron -cognitive improvements (with reductions of stress, anxiety, depression and probably delays in cognitive decline and dementia development in older patients) $[7,8]$ are well known and should also be considered.

With highly active antiretroviral therapy (HAART) introduction, we have witnessed a significant increase in survival and improvement in the quality of life of HIV infected patients in developed countries $[9,10]$. Consequently, common disease in general population (such as cardiovascular ones) [11] and side effects related to HAART (like lipodystrophy) have become a new focus of attention in these patients. In this way, physical activity has 
been recommended previously in HIV to induce favorable metabolic changes and reduce risk of cardiovascular disease [12-15]. Although its prevalence is really low in this population [16], according to its low cost probably regular physical activity interventions may be cost effective in HIV infected patients [17]. Indeed, aerobic exercise or a combination of aerobic and resistance progressive exercise (at least $30 \mathrm{~min} /$ day, 3 times a week for 4 weeks) may be safe [18] and beneficial in other parameters in HIV infected patients [17], such as psychological status, quality of life, anthropometric and metabolic cardiopulmonary and immunity function. Nevertheless, effectiveness of these interventions in HIV patients has not been well established, probably due to several limitations of most of the trials that has tried to investigate this point.

On the other hand, there is much scientific evidence that indicates that physical exercise training is not only appropriate but also warranted for patients with HIV/AIDS. Results from various Meta analyses suggest that constant or interval aerobic exercise at $60-80 \%$ of maximum $\mathrm{HR}$, or a combination of aerobic exercise and progressive resistance exercise for at least 20 minutes, three times a week for a minimum period of four weeks is beneficial and appears to be safe for adults living with HIV/AIDS [19].

Aerobics exercise has been used successfully in the treatment of diabetes [20] cardiovascular disease [21]. The benefits of regular exercise also extend to the population infected with HIV. Chronic HIV infection is associated with muscle wasting, muscle weakness, fatigue, impaired functional work capacity, depression, and decreased quality of life, which lead to disability and mortality. Exercise can positively affect many aspects of the physical and mental health of HIV-infected patients. HIV/AIDS poses serious risks to the health of millions around the globe. Despite decades of research, no cure or vaccine has been found to prevent this disease and the resultant morbidity and mortality. Therapies, such as steroid and growth hormone administration, are also effective in treating HIV related symptoms, but with serious side effects and increased cost [22]. The most commonly used of which is therapeutic exercise, are currently being explored to deal with symptoms and complications of chronic HIV infection without the unwanted side effects [23].

In the global rank, Ethiopia has the 5th largest number of people living with the virus. The epidemic started from a low base in the 1980s which spread rapidly in the 1990s and already an estimated 1.5 million Ethiopian adults and 250,000 children are living with the virus about $90 \%$ of the reported AIDS cases were between the age of 20 and 49, the most important ages from the economic and social points of view [24]. In 2011, adult HIV/AIDS prevalence in Ethiopia was estimated at 1.5 percent. From the total population of 84.3 million, approximately 1.2 million Ethiopians were living with HIV/AIDS in 2010 [25]. National models of HIV prevalence showed the incidence of HIV infection declined by over 25 percent between 2001 and 2009 [26].

\subsection{Statement of the Problem}

It was found that HIV-infected individuals self-reporting exercise participation had $107.5 \%$ higher CD4 counts when compared to HIV-infected individuals who denied exercise participation. Exercisers also displayed slower disease progression to AIDS, less symptom logy and decreased rates of mortality compared to non-exercisers [27]. Other studies have demonstrated no effects on CD4 cell numbers. That no relationship was found between CD4 cell counts and physical activity, but has been previously reported after exercise training, may mean that the positive change in CD4 cell counts is intensity dependent. Finally, it linked lower CD4 cell count levels with non-compliance to prescribed exercise [28].

Exercise training is contraindicated during rapid weight loss associated with an acute illness or an active opportunistic infection [29]. Although there are many possible opportunistic infections, pneumocystis carinii pneumonia (PCP) is the most common opportunistic infection, and scarring from PCP can affect cardiopulmonary status [30]. Tuberculosis (TB) is another opportunistic infection affecting cardiopulmonary status. Upper respiratory infections, anemia, fatigue, and diarrheas are common and should be monitored as well. Some patients may not be able to participate in prescribed activity due to advanced disease (CD-4 levels $<100$ cells $/ \mathrm{mm}^{3}$ ) Central nervous system, peripheral nervous system, and musculoskeletal complications can also limit the patient's ability to participate in exercise programs, and may need to be treated concomitantly. HIV-1 penetrates the nervous system within hours of infection, but complications may present at anytime during the progression of the illness [31]. From this point of view, this study was showed that the Effect of Floor Aerobics Exercise on Immunity Induction of People with HIV/AIDS; the case of "Yetessfa bisrat miskir Association", Dire-Dawa, Ethiopia. Thus, this study was designed to meet the following objectives.

\subsection{Objectives}

\subsubsection{General Objective}

The aim of this study is to investigate the effect of floor aerobics exercise on immunity induction of people living with HIV/AIDS at Dire Dawa City Administration.

\subsubsection{Specific Objectives}

- To examine the effect of floor aerobics exercise on immunity induction after exercising.

- To compare the effect of floor aerobics exercise on immunity induction in terms of sex difference.

\subsection{Limitation of the Study}

To conduct this study the researcher was challenged by the willingness of the study participants regarding to their way of life during the actual data collection through exercise intervention because it was affected the progress of the study. 


\section{Materials and Methods}

\subsection{Description of the Study Area and Study Period}

The floor aerobics exercise training program was held at Medhanialem Primary \& Secondary School training hall and the laboratory was conducted at Dill-Chora referral hospital (DCRH), Dire-Dawa City Administration (DDCA), Eastern Ethiopia. The DDC is located in the eastern part of Ethiopia. The administration is bordered by the Shinile Zone of the Somali National Regional State on the northwest, and northeast, and by the eastern Hararghie Region of the Oromia National Regional State on the south, southeast, and east. The city covers $11,732.6 \mathrm{msq}$ and lies in the Dechatu River, at the foot of a ring of cliffs that has been described as "somewhat like a cluster of tea-leaves in the bottom of a slop-basin with a latitude and longitude of $9^{\circ} 36^{\prime} \mathrm{N} 41^{\circ} 52^{\prime} \mathrm{E}$ of meridian; and located $515 \mathrm{~km}$ from Addis Ababa. The climatic condition of the DDCA region seems to be greatly influenced by its topography, which lies between $950-1250$ $\mathrm{m}$ above sea level, and which is characterized by warm and dry climate with a relatively low level of precipitation. The mean annual temperature of the city is about $25.04^{\circ} \mathrm{C}$. The average maximum temperature of the Administration is $31.40^{\circ} \mathrm{C}$, while its average minimum temperature is about $18.36^{\circ} \mathrm{C}$. The aggregate average annual rainfall that the region gets from these two seasons (March to April and August to September) is about $604 \mathrm{~mm}$ (Dire Dawa Administration document, 2011)

\subsection{Study Design}

Quantitative interventional study design was used to supplement the result of laboratory test.

\subsection{Source of Sample Population}

Among ART users from Yetessfa Bisrat Miskir Association (YBMA) 52 voluntary members was participated in this study. The association, 376 females and 254 males, a total of 630 victims are members with the only criterion being attending ART program. Members have the following advantages: to activate the right donation for the right person, for job opportunity, to deliver house to house voluntary service to others by 85 members of the association and participate in different training programs.

\subsection{Inclusion and Exclusion Criteria}

Based on the following inclusion criterion study participants were selected; subjects were living with HIV/AIDS and had no opportunistic diseases the last three months before the exercise training started and have taken antiretroviral drugs and voluntary to give $5 \mathrm{cc}$ blood sample once a month for three consecutive months. In addition, they had not been regularly exercising for at least six months prior to the beginning of the exercise training program. On the other hand, based on medical evidence and personal information of the subject that was unable to move, having opportunistic diseases and taking other drugs were not included in the study sample.

\subsection{Sampling Method and Sample Size Determination Technique}

Purposive sampling method was used due to the nature of the study and to keep the willingness of the study subjects to be included in the sample. Among ART users from YBMA, the study subjects were selected with the use of their full willingness for the study purpose and recruited until the required sample size reached.

\subsection{Source of Data and Procedures of Data Collection}

In this study primary data was used which generated from laboratory results. Data collection performed using quantitative techniques to explore factors that are not addressed via a qualitative survey. Based on the statistical data from laboratory tests determine the effect of floor aerobic exercise on immunity induction of people living with HIV/AIDS. The data collected from ART drug users from YBMA at DDCA. Qualified laboratory technicians, who had previous experience in sample collection and sample analysis process in related studies, participated as data collectors. They organized and facilitated the self- administrated sample collection and analysis process. The sample collectors collected blood samples, and analyzed immunological results from a given blood sample. Before collection of blood samples, the experimental group oriented and two cc of fresh blood sample collected from each study subject only one time on the same day of enrolment. Syringe, needle (vacationer holder), test tube, and gloves, cotton, alcohol (70\%), bed regent, facs flow regent (20 litter), thermal paper, A4 paper, pen, safety box, sample holder, Bed FACS count 1.5, CELL DYN 1800, was used at the laboratory of DCRH. Each sample labeled with the code corresponding to the participant by the laboratory technicians for identification purpose. The exercise training delivered three times per week in alternate days (Monday, Wednesday and Friday) for a consecutive three months with one hour sessions from $5: 45$ PM-6:45 PM. The blood samples were taken four times within three months, finally T-cells parameters analysis done on the same day.

\subsection{Quality Control}

To assure quality of the data, different measures was undertaken during different stages of the sample collection process: qualified and trained lab technicians was participated and one hour discussion was undertaken on how to do with the issue of client privacy and confidentiality particularly when they were taken blood samples and analysis of immunity result. A brief orientation session about the whole purpose of the research project was arranged for participants'. To improve quality data collection procedures during sample taking time, the sample collection was undertaken in a separate laboratory room. Data completeness was checked by supervisors and researcher. A pre exercises test was conducted three days prior to the start of actual data 
collection via floor aerobics training.

\subsection{Data Processing and Method of Analysis}

This data was analyzed by descriptive statistics using mean, standard deviation, mean difference and t-value. The data was represented by using tabulation and written explanation. The quantitative data that generated from laboratory test which enter into a computer in Microsoft soft office excel. Statistical analysis was performed using SPSS version 17.0 statistical software package by the researcher. Student's t-test used to test significant differences between pre and post tests of immunity result: T-cells, results with respect to sex difference. Mean difference with $95 \%$ confidence intervals (CI) was used to compare the effect of determinant factor.

\subsection{Ethical Clearance}

The study was approved by the School of Graduate Studies and then ethical clearance was obtained from the Ethical Review Committee of College of Health Science, Haramaya University on behalf of the ministry of Science and Technology and the license was given to the researcher for research purposes only. In addition to this, institutional permission was obtained from Dire Dawa HIV/AIDS prevention \& control office (DHAPCO), DDC branch before conducting the study. Through these ethical certificates, the chairman of the association was first briefed about the study before meeting with subjects. Then specifically, the participants were informed about the, purpose, duration, procedures, risk and benefits of the study as well as the participation was purely a voluntary activity and the right to participate not participates and stop participation was respected. Issues of confidentiality and anonymity was also maintained even if they were exposed by the laboratory technicians, investigator and assistance data collectors. Subjects signed a consent format. A separate room was prepared for blood sample taking each study subject in order to keep their privacy and confidentiality of their results to prevent from external pressure.

\section{Results and Discussions}

\subsection{Effects of Floor Aerobics Exercise on Immunological Results}

The mean comparison of CD4, CD8, CD3 and CD4/CD8 ratio of pre exercise test result (PETR) compared with post exercise test result (POETR) one, two and three showed that highly significantly difference at the probability level of $5 \%$. The higher mean value of CD4 CD3 and CD4/CD8 ratio was recorded at POET-3 with compared to PET value (Table 1). There was no significant difference obtained between POET one (POET-1) and POET-2 on CD4 (Table 1). This might be because most of subjects missed for the minimum of three up to six exercise sessions due to personal reasons. Even if CD8 cells/mm3 laboratory test analyses performed (Table 1) no significant changes in CD8 count were found among tests comparison. This might be an increment of CD4 value for participants following with aerobics exercise than PETR. The majority of non-significant findings are consistent with individual study results. Although not statistically significant, the point estimate is above 50 cells $/ \mathrm{mm}^{3}$, which suggests a potential clinically important increase in CD8 count for those who exercised compared with them.

Involving formal aerobic exercise training programs with the increments of duration, frequency, modality and intensity provide a crucial benefit on T-cells induction to individuals with HIV/AIDS seen in this study but intensity should not exceed the HR of 150 beats per minutes (physical work capacity-PWC 150), in order to avoid an immune depression induced by high intensity exercises. Although there seems to be controversy regarding the immune response with exercise, a review of the literature reveals exercise does not decrease CD-4 levels at any stage of the disease. In fact, there is a trend toward an increase in CD-4 levels. Exercise, especially when introduced early in the infection in those with HIV, can help stave off opportunistic infections [32].

Exercisers also displayed slower disease progression to AIDS, less symptom logy and decreased rates of mortality compared to non-exercisers. Other studies have demonstrated no effects on CD4 cell numbers [33]. That no relationship was found between CD4 cell counts and physical activity, but has been previously reported after exercise training, may mean that the positive change in CD4 cell counts is intensity dependent. Finally, it linked lower CD4 cell count levels with non-compliance to prescribed exercise. For these reasons, aerobic training has been used in many different forms as an intervention for HIV-infected persons. [34] Used an interval training method on a cycle ergo meter to examine changes in lymphocyte cell counts in 16 men who began exercising prior to undergoing HIV screening. Patients worked at $70 \%-80 \%$ maximum HR for three minutes followed by two minute sessions at a lower intensity. Findings showed that 45 minutes of training 3 times per week for 5 weeks significantly increased CD4+helper cell counts (904 vs. 1020 $\mathrm{mm}^{3}$ ) and the CD8+ inducer subset Cluster Designation 45 (CD45) RA+CD4+ (no quantification given) in those who presented as HIV positive.

A recent met analysis that included most of the mentioned trials, found no difference in change in CD4 count for participants in the exercise intervention group compared with the non-exercising control group [35]. Although this met analysis may be quite heterogeneous because included trials comparing more versus less intensive aerobic exercise, aerobic exercise against no other intervention, aerobic exercise and another intervention such as metformin [36] or lipid lowering diet [15] against aerobic exercise alone...) a significant trend towards an improvement in CD4 count of 69.58 cells $/ \mathrm{mm}^{3}$ for sub analysis exclusively of participants in the aerobic exercise trials compared with the nonexercising controls [35] was found. Besides that, the cutoff point estimated was above 50 cells $/ \mathrm{mm}^{3}$, which suggests a potential clinically important increase in CD4 count for interval exercisers compared with non-exercisers. 
Table 1. PET and POETs of T-cells, from YBMA in a selected training hall and DCRH, Dire Dawa.

\begin{tabular}{|c|c|c|c|c|c|c|c|}
\hline \multicolumn{8}{|c|}{ Paired Sample Test at $(\mathrm{N}=52)$} \\
\hline \multirow{2}{*}{ Dependent Variables } & \multicolumn{2}{|c|}{ Pre Exercise test (I) } & \multicolumn{2}{|c|}{ Pre Exercise test $(\mathrm{J})$} & \multirow[b]{2}{*}{ SD } & \multicolumn{2}{|c|}{ Paired Difference at $(\mathrm{df}=51)$} \\
\hline & Mean & SD & (J) Tests & Mean & & MD (J-I) & P-value \\
\hline \multirow{3}{*}{ CD4 } & \multirow{3}{*}{411.60} & \multirow{3}{*}{213.97} & POET-1 & 602.58 & 291.72 & 190.96 & 0.000 \\
\hline & & & POET-2 & 601.19 & 295.17 & 189.57 & 0.000 \\
\hline & & & POET-3 & 629.62 & 283.80 & 218.00 & 0.003 \\
\hline \multirow{3}{*}{ CD8 } & \multirow{3}{*}{872.60} & \multirow{3}{*}{377.80} & POET-1 & 961.69 & 363.45 & 89.08 & $0.085 \mathrm{NS}$ \\
\hline & & & POET-2 & 914.31 & 348.06 & 41.69 & $0.097 \mathrm{NS}$ \\
\hline & & & POET-3 & 976.62 & 307.24 & 104.00 & 0.049 \\
\hline \multirow{3}{*}{ CD3 } & \multirow{3}{*}{1326.00} & \multirow{3}{*}{475.79} & POET-1 & 1665.50 & 620.01 & 339.00 & 0.047 \\
\hline & & & POET-2 & 1625.60 & 568.14 & 299.12 & 0.004 \\
\hline & & & POET-3 & 1752.70 & 481.54 & 426.19 & 0.002 \\
\hline \multirow{3}{*}{$\mathrm{CD} 4 / \mathrm{CD} 8$} & \multirow{3}{*}{0.54} & \multirow{3}{*}{0.28} & POET-1 & 0.68 & 0.35 & 0.14 & 0.003 \\
\hline & & & POET-2 & 0.71 & 0.312 & 0.17 & 0.001 \\
\hline & & & POET-3 & 0.74 & 0.31 & 0.20 & 0.000 \\
\hline
\end{tabular}

Significant at $5 \%$

\subsection{Comparison of Immunological Results Between Females and Males}

A total of 52 people living with HIV/AIDS completed 60 minutes/ 3 day/week x 12 weeks. $26(50 \%)$ males and the remaining $26(50 \%)$ participants were females. The mean comparison of females and males T-cells cells $/ \mathrm{mm}^{3}$ of PETR with POETR showed that highly significantly difference at the probability level of 5\% except the mean value of male CD8 result because there was no significant difference obtained between PETR and PEOTR on CD8 cells $/ \mathrm{mm}^{3}$ result (Table 2). This might be because an increment of males CD4 cells $/ \mathrm{mm}^{3}$ after executed floor aerobics exercise than PET. The higher mean value of $\mathrm{CD} 4, \mathrm{CD} 8, \mathrm{CD} 3$ and $\mathrm{CD} 4 / \mathrm{CD} 8$ cells $/ \mathrm{mm}^{3}$ ratio obtained by females at PEOT with compared to PET value (Table 2). Male participants were obtained a greater amount of CD4 and CD4/CD8 ratio cells $/ \mathrm{mm}^{3}$ of mean difference than female. On the other hand females scored a greater amount of CD8 and CD3 cells $/ \mathrm{mm}^{3}$ mean difference than male (Table 2). Involving formal aerobic exercise training programs with the increments of duration, frequency, modality and intensity provide a crucial benefit on females and males T-cells induction to people with HIV/AIDS and also might have effects on T-cells count difference between females and male's HIV-infected individuals seen in this study. On consequence of differences in genetic attributes and circulating levels of sex steroid hormones which includes androgens, estrogens, and progesterone is that there are immunity differences between males and females. But in both sex the intensity should not exceed the HR of 150 beats per minutes (physical work capacity-PWC 150); in order to avoid an immune depression induced by high intensity exercises [37].

During and immediately after prolonged or heavy physical exercise, the total number of White blood cells (WBC) in peripheral blood samples increases [38]. Women have superior systemic immunity to men, leading to the hypothesis that this increased immune function imparts susceptibility to autoimmunity [39]. Women are reported to have higher serum antibody concentrations, numbers of CD4+ T cells and $\mathrm{CD} 4 / \mathrm{CD} 8$ ratios in blood, enhanced cytokine production in response to infections, stronger humoral and $\mathrm{T}$ cell responses to numerous antigens, greater resistance to infections, and greater ability to reject allograft and tumors [40]. The steroid sex hormones, estrogen and testosterone, are likely to directly modulate the function of cells involved in the immune response since lymphocytes and myeloid cells express estrogen (ER) and androgen receptors [41]. Estrogens are regulators of growth, differentiation, survival or function in many organ systems including the immune system [42].

Table 2. PET and PEOT females and males of T-cells, from YBMA in a selected training hall and DCRH, Dire Dawa.

\begin{tabular}{|c|c|c|c|c|c|c|c|}
\hline \multicolumn{8}{|c|}{ Paired Sample Test at $(\mathrm{N}=52)$} \\
\hline \multirow{2}{*}{ Dependent Variables } & \multirow{2}{*}{ Sex } & \multicolumn{2}{|c|}{ Pre Exercise test (I) } & \multicolumn{2}{|c|}{ Pre Exercise test $(J)$} & \multicolumn{2}{|c|}{ Paired Difference at $(\mathrm{df}=51)$} \\
\hline & & Mean & SD & Mean & SD & MD (J-I) & P-value \\
\hline \multirow{2}{*}{ CD4 } & $\mathrm{F}$ & 501.15 & 247.24 & 763.00 & 235.91 & 261.85 & 0.000 \\
\hline & M & 322.08 & 129.93 & 618.23 & 317.47 & 296.85 & 0.000 \\
\hline \multirow{2}{*}{ CD8 } & $\mathrm{F}$ & 811.23 & 278.88 & 981.23 & 243.69 & 170.00 & 0.003 \\
\hline & M & 934.00 & 459.80 & 972.00 & 370.43 & 38.00 & 0.058 \\
\hline \multirow{2}{*}{$\mathrm{CD} 3$} & $\mathrm{~F}$ & 1347.00 & 466.05 & 1833.6 & 338.20 & 486.61 & 0.042 \\
\hline & $\mathrm{M}$ & 1306.03 & 503.50 & 1671.83 & 595.41 & 365.77 & 0.049 \\
\hline \multirow{2}{*}{$\mathrm{CD} 4 / \mathrm{CD} 8$} & $\mathrm{~F}$ & 0.65 & 0.27 & 0.83 & 0.33 & 0.18 & 0.001 \\
\hline & M & 0.44 & 0.25 & 0.66 & 0.27 & 0.22 & 0.001 \\
\hline
\end{tabular}

Significant at $5 \%$ 


\section{Conclusions and Recommendations}

\subsection{Conclusions}

This research shows that moderate intensity floor aerobic exercise training implemented by trained professional is both safe and effective in HIV-infected persons. Finally this finding occluded that increasing duration, frequency, intensity and modality of floor aerobics exercise might have beneficial effects on immunity induction of people living with HIV/AIDS individuals and also might have effects on immunity induction difference between males and females HIV infected individuals due to sex based difference.

\subsection{Recommendations}

On the basis of the above results, discussion and conclusion the following recommendation were providing for proper implementation of floor aerobics exercise to assure immunity induction with regards to:

- People living with HIV/AIDS are advisable engaged in consistent and moderate intensity of floor aerobic exercise throughout the entire illness.

- The intensity should not exceed the heart rate of 150 BPM (physical work capacity); in order to avoid an immune depression induced by high intensity exercises.

- Floor aerobic exercise should not be recommended during rapid weight loss.

- People living with HIV/AIDS should be managed by multi-disciplinary sport science professionals and clinical nurses throughout the course of floor aerobic exercise.

\section{Acknowledgement}

First and foremost Praise is to the almighty GOD for the opportunity and capacity given me realize to my aspiration and enabling me compiles this thesis work. I owe my sincere thanks and compliments to my advisors Molla Deyou (PhD) and Shemiles Mekonnen $(\mathrm{PhD})$ for their guidance, kindness and encouragement during the entire span of my work. Second my special gratitude also goes to Yetessfa Bisrat Miskir Association members particularly for the study participants who took part in this study. Without them this study would not be possible. My deep gratitude also goes to Abayneh Kebede, coordinator of Yetessfa Bisrat Miskir Association for his invaluable support in bringing me the participants to take part in the study with a clear understanding. Third I am very grateful to Dire Dawa University for sponsoring this study to publish without which this study couldn't be possible. Fourth I am also thankful for the office of ethical review committee of College of Health Science, Haramaya University, for providing me a constructive professional comment, suggestions and necessary corrections during my thesis proposal writing up. Fifth I would also like to extend my thanks to Dill Chora Hospital covering all the necessary laboratory inputs and staffs who participated in this study as the data collectors, especially I express my deepest thanks to Dr. Abnet Eliayas, chief medical officer and Mr. Daniel Demssie, laboratory technician of Dill Chora Hospital. Six I am also thanks to Medhanialem Primary and Secondary School for providing me a training hall with the necessary facilities; especially I express my deepest thanks to Mr. Kebede Teferie, former director of Medhanialem Primary and Secondary School. Seventh Last but not least, my heartfelt gratitude goes to my families, colleagues and friends for their continuous encouragement and support in the accomplishment of this work.

\section{References}

[1] Proper KI, Singh AS, van Mechelen W, Chinapaw MJ (2011) Sedentary behaviors and health outcomes among adults: a systematic review ofprospective studies. Am J Prev Med 40: 174-182.

[2] Kodama S, Saito K, Tanaka S, Maki M, Yachi Y, et al. (2009) Cardiorespiratory fitness as a quantitative predictor of all cause mortality and cardiovascular events in healthy men and women: a meta-analysis. JAMA 301: 2024-2035.

[3] Wendel-Vos GC, Schuit AJ, Feskens EJ, Boshuizen HC, Verschuren WM, et al. (2004) Physical activity and stroke. A meta-analysis of observational data. Int J Epidemiol 33: 787798 .

[4] Yusuf S, Hawken S, Ounpuu S, Dans T, Avezum A, et al. (2004) Effect of potentially modificable risk factors associated with myocardial infarction in 52 countries (the INTERHEART study): case-control study. Lancet 364: 937-952.

[5] Michaud DS, Giovannucci E, Willett WC, Colditz GA, Stampfer MJ, et al. (2001) Physical activity, obesity, height, and the risk of pancreatic cancer. JAMA 286: 921-929.

[6] Meyerhardt JA, Giovanucci EL, Ogino S, Kirkner GJ, Chan AT, et al. (2009) Physical activity and male colorectal cancer survival. Arch Intern Med 169: 2102-2108.

[7] Herring MP, O'Conner PJ, Dishman RK (2010). The effect of exercise training on anxiety symptoms among patients: a systematic review. Arch Intern Med 170: 321-331.

[8] Martin CK, Church TS, Thompson AM, Earnest CP, Blair SN (2009) Exercise dose and quality of life: a randomized controlled trial. Arch Intern Med 169: 269- 278.

[9] Crum NF, Riffemburg RH, Wegner S, Agan BK, Tasker SA, et al. (2006) Comparisons of causes of death and mortality rates among HIV-infected persons: analysis of the pre-, early, and late HAART (highly active antiretroviral therapy) eras. J Acquir Immune Defic Syndr 41: 194-200.

[10] Sterne JA, Hernán MA, Ledergerber B, Tilling K, Weber R, et al. (2005) Longterm effectiveness of potent antiretroviral therapy in preventing AIDS and death: a prospective cohort study. Lancet 366: 378-384.

[11] Friis-Møller N, Sabin CA, Weber R, d'Arminio Monforte A, El-Sadr WM, et al. (2003) Combination antiretroviral therapy and the risk of myocardial infarction. $\mathrm{N}$ Engl J Med 349: 1993-2003. 
[12] Mutimura E, Stewart A, Crowther NJ, Yarasheski KE, Cade WT (2008) The effects of exercise training on quality of life in HAART-treated HIV-positive Rwandan subjects with body fat redistribution. Qual Life Res 17: 377-385.

[13] Robinson FP, Quinn LT, Rimmer JH (2007) Effects of highintensity endurance and resistance exercise on HIV metabolic abnormalities: a pilot study. Biol Res Nurs 8: 177-185.

[14] Lindegaard B, Hansen T, Hvid T, van Hall G, Plomgaard P, et al. (2008) The effect of strength and endurance training on insulin sensitivity and fat distribution in human immunodeficiency virus-infected patients with lipodystrophy. J Clin Endocrinol Metab 93: 3860-3869.

[15] Terry L, Sprinz E, Stein R, Medeiros NB, Oliveira J, et al. (2006) Exercise training in HIV-1-infected individuals with dyslipidemia and lipodystrophy. Med Sci Sports Exerc 38: 411-417.

[16] Barros CR, Zuchhi EM, Franca Junior I (2010) Physical activity level among Children and adolescents orphaned by AIDS. Rev Bras Epidemiol 13: 446-456.

[17] Ogalha C, Luz E, Sampaio E, Souza R, Zarife A, et al. (2011) A Randomized, Clinical Trial to Evaluate the Impact of Regular Physical Activity on the Quality of Life, Body Morphology and Metabolic Parameters of Patients With AIDS in Salvador, Brazil. J Acquir Immune Defic Syndr 57: S 179185 .

[18] O’Brien K, Nixon S, Tynan AM, Glazier RH (2008) Aerobic exercise interventions for people living with HIV/AIDS: Implications for practice, education and research. Physiother Can 58: 114-129.

[19] O'Brien K, Nixon S, Tynan AM, Glazier R (2010) Aerobic exercise interventions for adults living with HIV/AIDS. Cochrane Database Syst Rev 4: CD001796.

[20] Albright, A., M. Franz, G. Hornsby, A. Kriska, D. Marrero, and Ullrich, 2000. American college of Sport Medicine positions stand. Exercise and type two diabetes. Journal of Medicine and Science in Sports and Exercise, 32 (7), 13451360.

[21] American College of Sports Medicine. 1994. American College of Sports Medicine position stand and exercise for patients with coronary artery disease. Journal of Medicine and Science in Sports and Exercise, 26, 1-5.

[22] Basaria, S., J. T. Wahlstrom, and A. S. Dobs, 2001. Clinical review 138: Anabolicandrogenic steroid therapy in the treatment of chronic diseases. Journal of Clinical Endocrinology and Metabolism, 86 (11), 5108-5117.

[23] Standish, L. J., K. B. Greene, S. Bain, C. Reeves, F. Sanders, R. C. Wines, 2001. Alternative medicine use in HIV positive men and women: Demographics, utilization patterns and health status. AIDS Care, 13 (2), 197-208.

[24] Ministry of Health. 2005a. Accelerating Access to HIV/AIDS Treatment in Ethiopia: Road Map for 2004-2006, Addis Ababa. (Cited by Scott Drimie, Getahun Tafesse \&Bruce Frayne, January, 2006)

[25] Central Statistical Agency of Ethiopia, 2011. Ethiopia Demographic and Health Survey. Addis Ababa, Ethiopia and Calverton, Maryland, USA: Central Statistical Agency and ICF International 2012.
[26] WHO, UNAIDS, UNICEF. 2011. Global HIV/AIDS Response: Epidemic Update and Health Sector Progress towards Universal Access. Geneva, Switzerland.

[27] Mustafa, T., F. S. Sayer, C. A. Macera, S. J. Thompson, K. L. Jackson, A. Selassie, 1999. Association between exercise and HIV disease progression in a cohort of homosexual men. Journal of Annals of Epidemiology, 9 (2), 127-131.

[28] MacArthur, R. D., S. D. Levine, and T. J. Birk, 1993. Supervised exercise training improves cardiopulmonary fitness in HIV infected persons. Journal of Medicine and Science in Sports and Exercise, 25 (6), 684-688.

[29] Yarasheski KE., R. Roubenoff, 2001. Exercise treatment for HIV-associated metabolic and anthropomorphic complications. Journal of Exerc Sport Sci Rev. 29: 170-174

[30] Perry, AC, A. LaPerriere, N. Klimas, 2003. Acquired immune deficiency syndrome (AIDS). In: Durstine JL, Moore GE, eds. American College of Sports Medicine's Exercise Management for Persons with Chronic Diseases and Disabilities. 2nd ed. Champaign, Ill: Human Kinetics: 173-179.

[31] Clifford, D. B., 1998. Neurologic complications of human immunodeficiency virus infection. Neurologist; 4: 54-65.

[32] Galantino, M. L., 2001. Human immunodeficiency virus (HIV) infection, living with a chronic illness. Neurological Rehabilitation. 4th ed. St. Louis, Mo: Mosby; 553-575.

[33] Smith, B. A., J. L. Neidig, J. T. Nickel, G. L. Mitchell, M. F. Para, and R. J. Fass, 2001. Aerobic exercise: Effects on parameters related to fatigue, dyspnoea, weight and body composition in HIV-infected adults. AIDS, 15 (6), 693-701.

[34] LaPerriere, A., M. A. Fletcher, M. H. Antoni, N. G. Klimas, G. Ironson, and N. Schneiderman, 1991. Aerobic exercise training in and AIDS risk group. International Journal of Sports Medicine, 12 (Suppl. 1), S53-S57.

[35] O'Brien K, Nixon S, Tynan AM, Glazier R (2010) Aerobic exercise interventions for adults living with HIV/AIDS. Cochrane Database Syst Rev 4: CD001796.

[36] Driscoll SD, Meininger GE, Lareau MT, Dolan SE, Killilea $\mathrm{KM}$, et al. (2004) Effects of exercise training and metformin on body composition and cardiovascular indices in HIVinfected patients. AIDS 18: 465-473.

[37] American College of Sports Medicine. 2000. Physical fitness, testing, and interpretation and in American College of sports medicine guidelines for exercise testing and prescription. 6th edition, Baltimore: Lippincott, Williams \& Wilkins. pp. 57-90.

[38] Rowbottom, D. G., K. J. Green, 2000, Acute Exercise Effects on the Immune System. Journal of Medicine \& Science in Sports and Exercise, 37 (2): 396-405.

[39] Whitacre, C. C., S. C. Reingold, P. A. O'Looney, 1999. Science, 283, 1277.

[40] Olsen, N. J., W. J. Kovacs, J. Gend, 2002. Specif. Med. 5, 28.

[41] Komi, J., O. Lassila, 2000. Effect of aging on gender differences in neural control Blood, 95, 2875.

[42] Kim, S., S. M. Liva, M. A. Dalal, M. A. Verity, R. R. Voskuhl, 1999. Neurology, 52, 1230. 